\title{
Seasonal, Spatial Distribution and Ecological Risk Assessment of Heavy Metals in Surface Sediments from a Watershed Area in Gonghu Bay in Taihu Lake, China
}

\author{
Peifang Wang, Jiajia Liu, Chao Wang *, Jin Qian, Jun Hou, and Lingxiao Ren \\ Key Laboratory of Integrated Regulation and Resource Department on Shallow Lakes, Ministry of Education, \\ College of Environment, Hohai University, Nanjing, PR China
}

Received 21 October 2013, revised 10 January 2014, accepted 17 February 2014

\begin{abstract}
Surface sediments from five stations within Gonghu Bay in Taihu Lake, China, were sampled for seasonal and spatial metal contamination analysis variations and ecological risks assessment from April 2009 to January 2010. The Contamination Factor (CF) and geo-accumulation index (Igeo) indicated that the sediments in Gonghu Bay ranged from unpolluted to moderately polluted, except for $\mathrm{Cd}$. The one-way ANOVA analysis results showed that the $\mathrm{Pb}, \mathrm{Zn}, \mathrm{Cr}$, and $\mathrm{Cu}$ concentrations were higher at station 3 (lake inlet) and the $\mathrm{Cr}, \mathrm{Pb}$, and $\mathrm{Zn}$ concentrations were significantly higher in the spring. Additionally, using BCR's sequential extraction, the results showed that the fractionated metals $\mathrm{Zn}$ and $\mathrm{Cd}$ were observed as bioavailable fractions in the sediments, which could have potential moderate mobility in the water system. There was a significant increase in the bioavailable form during winter. The ratio of secondary and primary phrase (RSP) decreased according to the order $\mathrm{Zn}>\mathrm{Cu}>\mathrm{Ni}>\mathrm{Pb}>\mathrm{Cd}>\mathrm{Cr}$. Finally, these results indicated that the sediments of Gonghu Bay were polluted by $\mathrm{Cd}, \mathrm{Zn}$, and $\mathrm{Cu}$, which provides a scientific basis for effectively protecting sediments in watershed areas from long-term heavy metal accumulation.
\end{abstract}

Key words: Sediment, Heavy metals, Seasonal and spatial distribution, Ecological risk assessment

Citation: Wang, P., J. Liu, C. Wang, J. Qian, J. Hou, and L. Ren, 2014: Seasonal, spatial distribution and ecological risk assessment of heavy metals in surface sediments from a watershed area in Gonghu Bay in Taihu Lake, China. Terr. Atmos. Ocean. Sci., 25, 605-616, doi: 10.3319/TAO.2014.02.17.01(Hy)

\section{INTRODUCTION}

Heavy metals are inert in sediment environments and often considered to be conservative pollutants (Lim et al. 2008; Guven and Akinci 2013). Most heavy metals that are attached to suspended solids (SS) will fall to the bottom of lakes, rivers and other bodies of water. A static mass transfer balance is established between the water and the sediment in an entire natural water ecosystem. Heavy metals in sediment are harmful to lake aquatic ecosystems, not only in terms of total content but also in terms of the geometrical shape of the molecules, which are more relevant to biological toxicity (Förstner 1993; Yang et al. 2012). Heavy metals in sediments may re-enter the aqueous phase in a much more toxic form, which then introduces potential ecological risks to aquatic organisms (Arnason and Fletcher 2003;

\footnotetext{
* Corresponding author

E-mail:cwang@hhu.edu.cn
}

Singh et al. 2005). Contamination factor (CF) has been widely used to study the sources and contamination of trace metals in riverine environments (Wedepohl 1995; Pekey et al. 2004). Another commonly used criterion to evaluate the heavy metal pollution in sediments is the geo-accumulation index (Igeo) originally introduced by Müller (1969) which determines and defines metal contamination in sediments by comparing current concentrations with pre-industrial levels. Similar to the metal CF, the geoaccumulation index can be used as a reference to estimate the extent of metal pollution. The total concentration of soil heavy metal is a useful indicator of contamination assessment. However, the mobility of heavy metals, as well as their bioavailability and related eco-toxicity to plants, depend greatly on their forms (Jin et al. 2005; Chen et al. 2008). The ratio of secondary and primary phrase (RSP) can provide enough information about the bioavailability and toxicity of heavy metals (Chen et al. 1987). In watershed areas, heavy metals or special groups 
of contaminants affect environmental quality by accumulating in sediments, which results in serious human health hazards and significant ecological effects throughout the food chain. The quantification of heavy metals in lake sediments has been used extensively for pollution monitoring (Pekey et al. 2004; Liu et al. 2007). In this study, we focus on the seasonal and spatial distributions of the total amounts and chemical forms of heavy metals and the pollution assessments for watershed areas.

Taihu Lake is the third largest freshwater lake in China and is situated on the southern Yangtze River Delta. It is the most developed area and has the highest population density in China (Shen et al. 2001). Human impacts have increased severely since the 1980s and many types of industrial companies have been established in this watershed. Consequently, Taihu Lake has been recognized as a heavily contaminated area by $\mathrm{Pb}, \mathrm{Cu}$, and $\mathrm{Zn}$ due to the increasing discharge of pollutants (Jin et al. 2010; Yao and Xue 2010). Gonghu Bay, which is located in the northeast area of Taihu Lake, is an important source of drinking water for the cities of Wuxi and Suzhou. There are three main drinking water sources distributed across Gonghu Bay, where the water quality is directly related to the safety of the drinking water. However, the environment surrounding the bank of Gonghu Bay is not a promising source of safe drinking water. Industrial wastewaters and sewage are discharged into Gonghu Bay from the Wuxi industrial zone in the north of Taihu Lake, which contain a large amount of heavy metals, such as $\mathrm{Cd}$ and $\mathrm{Zn}$ from the production of rubber and $\mathrm{Cu}$ from metal plating processes, threatening the safety of the water supply.

To improve water quality and control eutrophication the Chinese government has been performing water conduction engineering from the Yangtze River through the Wangyu River to Taihu Lake since 2002. Water quality, as indicated by $\mathrm{COD}_{\mathrm{Mn}} \mathrm{NH}_{3}-\mathrm{N}$, has improved, but many of the SS imported into the lake and sediment are still passed through the water, which is an important factor in transferring trace elements and changing the content of the sediments in Taihu Lake. Yuan (Yuan et al. 2004) examined the top $10 \mathrm{~cm}$ layer of sediments at 16 sites in three sub-areas of Taihu Lake and found that the concentrations of $\mathrm{Cu}$ and $\mathrm{Cr}$ are high in Gonghu Bay. Because Gonghu Bay was regarded as an unpolluted or low-polluted area of Taihu Lake (Huang et al. 2009), little attention has been paid to heavy metal pollution in the sediments of Gonghu Bay and the potential ecological risks associated with it.

The objectives of this paper are (1) to investigate the seasonal and spatial distributions of heavy metals in the surface sediments of a watershed area in Gonghu Bay; (2) to reveal the pollution status caused by heavy metals in surface sediments using the CF and Igeo; and (3) to evaluate heavy metal ecological risks using the RSP approach, which provides a scientific basis for the comprehensive evaluation and pollution regulation of Gonghu Bay.

\section{MATERIALS AND METHODS}

\subsection{Study Area - Gonghu Bay, Taihu Lake}

Gonghu Bay, which is situated in the northeast area of Taihu Lake, is the largest of the numerous bays on the lake (see Fig. 1). The total water area of this bay is $147 \mathrm{~km}^{2}$. It is a shallow lake wetland with an average water depth of $2 \mathrm{~m}$, and the surface sediments have a fairly neutral $\mathrm{pH}$ ranging from 6 to 7 . Many aquatic plants have grown in the northeast area of the lake, and the largest biomass concentrations can be up to $11.2 \mathrm{~kg} \mathrm{~m}^{-2}$ (Fan et al.1997). The lake's ecosystem has been significantly impacted by anthropogenic activities, such as the discharge of industrial and domestic effluents (Zhai et al. 2010). Significant industrial wastes come mainly from Wuxi and Suzhou cities and are discharged into the lake by the surrounding rivers. Chemicals are not easily diluted due to the semi-closed shape of Gonghu Bay. Only the southwestern border of Gonghu Bay is connected to Taihu Lake. In recent years, the ecological system of Gonghu Bay has gradually degraded due to high nitrogen and phosphorus nutrient loads and the influence of algal blooms. In 2007, a serious water crisis event occurred due to a blue-green algae outbreak that threatened the normal lives of the residents of Suzhou and Wuxi. The eutrophication of Taihu Lake in the summer seriously affects the quality of available drinking water and although the water quality indicators are relatively higher in the winter, water safety has become a serious concern. Therefore, seasonal assessments of the current water quality situation and the prevention of the deterioration of the water environment are of vital importance.

This study obtained surface sediments from Gonghu Bay where the water conduction has the greatest influence. Heavy metals $\mathrm{Cr}, \mathrm{Cu}, \mathrm{Zn}, \mathrm{Pb}, \mathrm{Cd}$, and $\mathrm{Ni}$ were present and their biochemical forms were analyzed using the four-step sequence abstraction method (BCR) to study the mobilization characteristics of each element. The differences in the concentrations of each element in the surface sediment among different seasons were analyzed to determine the spatial and time variation effects. The results may yield some insights about heavy metal pollution in the surface sediments of Taihu Lake.

\subsection{Sediment Sampling}

Based on the physical properties of the sediments in terms of hydrodynamics, five sampling stations were selected, as shown in Fig. 1. Station 1 is near the water intake of the Baiyangwan water works, station 3 is near the Xidong water plant, and station 5 is near the Gonghu south spring water plant. These three water plants supply water to the nearby towns. The intake water quality is directly related to the safety of the drinking water supplied to residents. Water and composite sediment samples were collected from five different areas of Gonghu Bay from all directions and in all 
four seasons (April 2009-spring, July 2009-summer, September 2009-Autumn, and January 2010-winter). Sediment samples were collected using a grab sampler and placed in pre-cleaned polyethylene bags. The samples were transferred to the laboratory in an icebox and processed within 18 - $24 \mathrm{~h}$. Before analysis the sediment samples were dried, ground, sieved with a 100-mesh sieve and stored in plastic containers that had been cleaned with $1: 1 \mathrm{HNO}_{3}$.

\subsection{Metal Extraction and Analysis}

Freeze-dried sediment aliquots were ground, homogenized and digested on a hot plate with ultrapure $6 \mathrm{ml} \mathrm{HNO}_{3}$, $1 \mathrm{ml} \mathrm{H}_{2} \mathrm{O}_{2}, 4 \mathrm{ml} \mathrm{HF}$, and $0.5 \mathrm{ml} \mathrm{HCLO}$. After complete digestion the acids were evaporated to near dryness and the residues re-dissolved in $1 \mathrm{~mol} \mathrm{l}^{-1} \mathrm{HNO}_{3}(\mathrm{McLaren}$ and Kim 1995). The heavy metal concentrations in the final solutions were determined using ICP-AES using a volume-based flow injection procedure. Three duplicates of $0.2 \mathrm{~g}$ of each sample were measured. Blank extraction (without sample) was carried out throughout the entire procedure.

The BCR sequential extraction procedure described by Wang (Wang et al. 2006) was employed to extract the metal fractions in the sediment. The sample weight of the dried sludge was $0.50 \mathrm{~g}$. Extractions 1 through 4 were performed as Table 1 at room temperature for the indicated times. Separation between steps was performed by decantation of the supernatant after centrifugation at $4000 \mathrm{rpm}$ for $20 \mathrm{~min}$.

$\mathrm{F} 1$ is the acid soluble state including the water soluble state and the exchangeable state. This form is the most likely to affect the environment, while the carbonate combination state of metals in acid conditions is released easily. F2 is the reducible form, especially for Fe-Mn oxide combination state metals. When the redox potential is reduced or there is an oxygen deficit, the heavy metals can be easily restored and may cause secondary pollution. This form can reflect the effects of human activities on environmental pollution (O'Reilly Wiese et al. 1997). F3 is the oxidation state, including organic matter and the sulfide combination state of metals, which can be released under strong oxidation conditions. The organic combination state reflects aquatic biological activities and the discharge of wastewaters rich in organic materials (Yang et al. 2009). F4 is the residual form, where the main state is mineral crystals. Under natural conditions, it is not easily released and has little effect on toxicity to animals and plants and biological effectiveness.

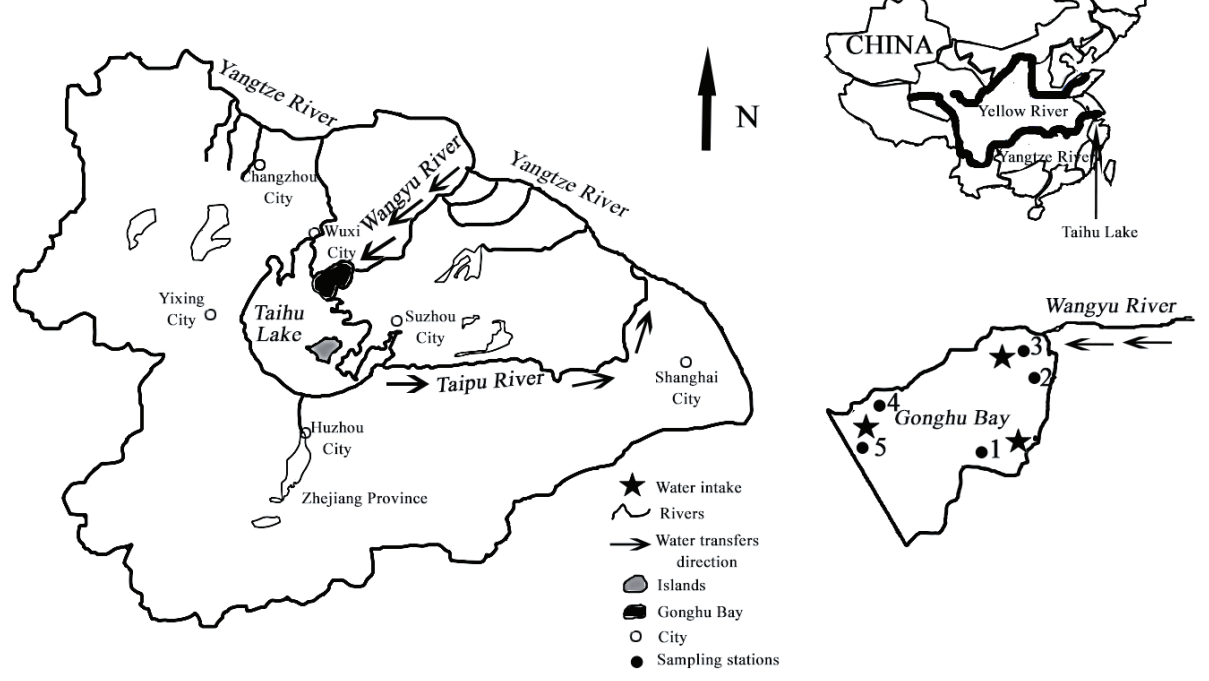

Fig. 1. Map of Gonghu bay and water transfer routes.

Table 1. Extractants used at each extraction step and the extraction phases of sediments in the sequential extraction procedure.

\begin{tabular}{clc}
\hline Extraction steps & \multicolumn{1}{c}{ Reactive/concentration/pH } & Sediment phase \\
\hline 1 & Acetic acid $\mathrm{CH}_{3} \mathrm{COOH}\left(0.11 \mathrm{~mol} \mathrm{l}^{-1}\right), \mathrm{pH}<2$ & Exchangeable, water and acid soluble \\
2 & Hydroxyl ammonium chloride $\mathrm{NH}_{2} \mathrm{OH} \cdot \mathrm{HCI}\left(0.1 \mathrm{~mol} \mathrm{l}^{-1}\right), \mathrm{pH}<2$ & Reducible \\
3 & Hydrogen peroxide $\mathrm{H}_{2} \mathrm{O}_{2}\left(9.8 \mathrm{~mol} \mathrm{l}^{-1}\right)+$ ammonium acetate $\mathrm{CH}_{3} \mathrm{COONH}_{4}\left(1 \mathrm{~mol} \mathrm{l}^{-1}\right), \mathrm{pH}<2$ & Oxidizable \\
4 & Aqua regia $\left(5 \mathrm{HNO}_{3}+4 \mathrm{HF}+1 \mathrm{H}_{2} \mathrm{O}_{2}\right)$ & Residual \\
\hline
\end{tabular}


For all metals, the agreements between total metal values and extractable metal values were generally acceptable $(100 \pm 10 \%)$, which indicate that the potential increased recovery through the fractional procedure has not occurred and that the experiment results are credible.

\subsection{Statistical Analysis}

A Pearson correlation analysis was employed to better understand the relationships among the concentrations of various metals, sediment type, $\mathrm{pH}, \mathrm{TOC}$, Eh, and CEC using the SPSS version 17.0 statistical package. One-way ANOVA was employed to understand the variations in the heavy metals concentrations with respect to different stations and seasons.

\section{RESULTS AND DISCUSSION}

\subsection{Physical and Chemical Parameters of the Sediment}

The physical-chemical parameters of the sediments from Gonghu Bay are given in Table 2. Most of the samplings studied were characterized by a neutral or slight alkalinity with a mean $\mathrm{pH}$ value of 7.4 and a very low relative standard deviation (RSD 6.2\%). The heavy metal contents increased significantly with the $\mathrm{pH}$ between $6.5-7.5$. However, the heavy metal contents decreased in alkaline soil samples when the $\mathrm{pH}$ was over 7.5 (Hellweg et al. 2005; Kuo et al. 2006; Li et al. 2009). The Cation Exchange Capacity ranged from 12.36 - $99.15 \mathrm{cmol} \mathrm{kg}^{-1}$, which was relatively high, indicating that heavy metals could easily be released from the sediments to the water and pore water.

The total organic carbon (TOC) content ranged from $7.64-32.98 \mathrm{~g} \mathrm{~kg}^{-1}$, with a mean value of $20.63 \mathrm{~g} \mathrm{~kg}^{-1}$. The moderate variability of TOC content among different samplings, RSD 23\%, could be due to the different rates of the mineralization processes. Terry et al. (1979) stated that $26-42 \%$ of the organic matter introduced with sludge very quickly undergoes mineralization, whereas the remainder is clearly resistant to decomposition. The TOC content is higher in the samplings near the bank of Gonghu Bay because of the influence of sewage from downtown.

The particle size of sediment is one of the most important controlling parameters for heavy metal content (Horowitz and Elrick 1987). With reference to the commonly accepted particle size classification scheme (Udden-Wentworth), this study classified the particle sizes of the surface sediments in Gonghu Bay into sand $(2-0.063 \mathrm{~mm})$, silt $(0.063-0.0039 \mathrm{~mm})$ and clay $(<0.0039 \mathrm{~mm})$. The particle sizes in the surface sediments of Gonghu Bay are shown in Table 2, where silt comprises the majority of the sediment (62.62 - 73.66\%, average $69.18 \%$ ). The sand content along the southeast coast of Gonghu Bay is greater than the other locations, and the overall average of sand composition is $18.73 \%$. The average clay content is $12.10 \%$.
The period of water conduction from the Yangtze River was from April 28 to 29, in 2009, therefore, samples were taken from April 24 to 28 in the spring before the period, from July 2 to 6 in the summer, from September 18 to 22 in the autumn and from January 23 to 27 in the winter after the period. The present study shows that the average particle size of all samplings is $0.0742 \mathrm{~mm}$. However, the Administration of Taihu Lake Basin from the Ministry of Water Resources has found that the main component of the surface sediment is thick powder sand with clay, with an average particle size of $0.0323 \mathrm{~mm}$ in the vicinity of Gonghu Bay (Fan and Zhang 2009). The introduction of water from the Wangyu river may cause the average particle size on the southeast coast of Gonghu Bay to be significantly higher than in other areas of the lake. The particle size in the surface sediment of all samplings ranged from $0.032-0.139 \mathrm{~mm}$, where station 3 showed the largest value and particle sizes were larger closer to the water input.

\subsection{Total Content of Heavy Metals}

The metal concentrations showed wide variations, as shown in Table 3 (in $\mathrm{mg} \mathrm{kg}^{-1}$ ): $\mathrm{Pb}, 18.03-55.20 ; \mathrm{Cu}$, 20.52 - 78.8; Zn, 40.54 - 456.63; Cd, 0.70 - 6.23; Ni, 21.55 - 203.72; and Cr, 43.28 - 106.64.

The release of these metals into the urban environment is often associated with battery manufacturing, pigments and paints and printing and graphic activities (Alloway and Ayres 1997). These activities occur in the industrial area of Wuxi. When analyzing the RSD, it was found that the $\mathrm{Cr}$ and $\mathrm{Pb}$ contents showed the lowest RSD in all sediments. Yuan (Yuan et al. 2011) found that the concentrations of $\mathrm{Cu}$ and $\mathrm{Cr}$ are high in the northern bays of Taihu Lake, while $\mathrm{Zn}$ is high in Meiliang Bay and along the western shore.

The overall average selected heavy metals concentrations in the Gonghu Bay sediments were up to the background values of continental sediments. $\mathrm{Pb}$ and $\mathrm{Cr}$ were below the primary standard criteria of the Soil Environmental Quality Standards, while $\mathrm{Cu}, \mathrm{Zn}, \mathrm{Cd}$, and $\mathrm{Ni}$ were close to the standard criteria values. $\mathrm{Cd}$ and $\mathrm{Zn}$ exceeded the standards significantly. In this sense it is indicated that the $\mathrm{Cr}$ and $\mathrm{Ni}$ levels found in our study were generally within the common ranges and typical background metals concentrations in sediments. The $\mathrm{Cd}, \mathrm{Cu}, \mathrm{Pb}$, and $\mathrm{Zn}$ contents were higher in the sediments than those generally found in natural sediments, as shown in Table 3 (Kabata-Pendias and Pendias 2001). Such results are typical for lake sediments (De Miguel et al. 1998). The high heavy metals contents are probably related to the origin of these materials, which is essentially an area with a large presence of heavy industrial plants. However, although the total heavy metals contents in the sediments are below the control standards for pollutants in sludge from agricultural use, metals could affect the pool that exists naturally in soils when sludge is used in agriculture. 
Table 2. Physical-chemical parameters of sediments from Gonghu Bay.

\begin{tabular}{|c|c|c|c|c|c|c|c|}
\hline \multirow{2}{*}{ Samplings } & \multirow{2}{*}{ pH } & \multirow{2}{*}{ Eh $(\mathbf{m v})$} & \multirow{2}{*}{$\mathrm{CEC}\left(\mathrm{cmol} \cdot \mathrm{kg}^{-1}\right)$} & \multirow{2}{*}{ TOC $\left(\mathrm{g} \mathrm{kg}^{-1}\right)$} & \multicolumn{3}{|c|}{ Particle size } \\
\hline & & & & & $<3.9 \mu \mathrm{m}(\%)$ & $3.9-63 \mu \mathrm{m}(\%)$ & $63-2000 \mu \mathrm{m}(\%)$ \\
\hline $1^{\mathrm{a}}$ & $7.3 \pm 0.2$ & $88.3 \pm 12.5$ & $51.4 \pm 32.5$ & $13.0 \pm 5.5$ & $8.1 \pm 5.9$ & $74.2 \pm 7.3$ & $17.8 \pm 9.38$ \\
\hline $2^{\mathrm{a}}$ & $7.6 \pm 0.1$ & $20.7 \pm 7.3$ & $79.4 \pm 17.0$ & $22.5 \pm 9.3$ & $5.9 \pm 6.4$ & $61.6 \pm 17.9$ & $32.5 \pm 20.7$ \\
\hline $3^{\mathrm{a}}$ & $7.3 \pm 0.2$ & $70.0 \pm 16.3$ & $27.1 \pm 9.3$ & $19.5 \pm 7.0$ & $9.4 \pm 8.4$ & $78.4 \pm 5.6$ & $12.2 \pm 7.3$ \\
\hline $4^{\mathrm{a}}$ & $7.4 \pm 0.1$ & $164.8 \pm 27.3$ & $19.3 \pm 5.7$ & $9.9 \pm 2.5$ & $8.8 \pm 7.3$ & $73.8 \pm 4.4$ & $17.7 \pm 8.6$ \\
\hline $5^{\mathrm{a}}$ & $7.5 \pm 0.1$ & $216.3 \pm 37.3$ & $19.5 \pm 4.7$ & $9.7 \pm 1.7$ & $8.8 \pm 6.1$ & $70.5 \pm 8.8$ & $20.7 \pm 5.7$ \\
\hline Mean $^{\mathrm{b}}$ & $7.4 \pm 0.1$ & $112.0 \pm 20.3$ & $39.3 \pm 25.9$ & $14.9 \pm 5.8$ & $8.2 \pm 1.3$ & $71.6 \pm 6.3$ & $20.2 \pm 7.5$ \\
\hline
\end{tabular}

Note: Each value represents the mean of the samples collected from 2009 to 2010.

${ }^{a}$ Mean value \pm standard deviation at each site.

${ }^{b}$ Mean value \pm standard deviation for all the sites.

Table 3. Comparison of metal concentrations in the sediments of Gonghu Bay according to different standards $\left(\mathrm{mg} \mathrm{kg}^{-1}\right)$.

\begin{tabular}{lcccccc}
\hline \multicolumn{1}{c}{ Metal } & Pb & Cu & Zn & Cd & Ni & Cr \\
\hline $\max$ & 55.20 & 78.81 & 456.63 & 6.23 & 203.72 & 106.64 \\
$\min$ & 18.03 & 20.52 & 40.54 & 0.70 & 21.55 & 43.28 \\
mean & 29.04 & 36.25 & 143.35 & 3.02 & 48.75 & 70.73 \\
SD & 9.75 & 16.96 & 84.34 & 1.45 & 19.36 & 16.57 \\
RSD (\%) & 33.6 & 46.8 & 51.0 & 48.1 & 39.4 & 23.4 \\
Background values of continental sediments & 20 & 20 & 65 & 0.1 & 28 & 70 \\
Soil Environmental Quality Standards (GB 15618) primary standard criteria & 35 & 35 & 100 & 0.20 & 40 & 90 \\
Control standards for pollutants in sludges from agricultural use (GB 4284-84) & 1000 & 500 & 1000 & 20 & 200 & 1000 \\
\hline
\end{tabular}

\subsubsection{Seasonal and Spatial Variability of Heavy Metals}

Figure 2 shows the distribution of the heavy metals contents in the different sediments during different seasons. Using one-way ANOVA analysis the total contents of $\mathrm{Cr}, \mathrm{Ni}$, $\mathrm{Pb}$, and $\mathrm{Zn}$ were found to significantly differ across the seasonal periods. It is interesting to note that $\mathrm{Cr}, \mathrm{Pb}$, and $\mathrm{Zn}$ displayed significantly higher concentrations during the spring.

The heavy metal contents of $\mathrm{Cr}, \mathrm{Pb}$, and $\mathrm{Zn}$ are highest in spring, probably because of the temperature, $\mathrm{pH}$, Eh in the lake are moderate during the spring. Because the proportions of fine particles $(<63$ muon $\mathrm{m}$ ) and organic components and the AVS content are the highest in Taihu lake sediments during the spring, these conditions are conducive for sediment to be adsorbed and combined with heavy metals (Hellweg et al. 2005; Kuo et al. 2006). In addition, decayed hydrobiological residues from the previous year are reserved in sediments and new aquatic organisms have not begun to grow in sediments, so the effects of biological activities are still relatively small.

The heavy metal contents of $\mathrm{Zn}, \mathrm{Cd}, \mathrm{Mn}$, and $\mathrm{Cr}$ are lowest during the summer, possibly because the water temperature of Taihu Lake is higher $\left(22.8^{\circ}-29.0^{\circ} \mathrm{C}\right)$ in the summer and Eh is relatively high, so the heavy metals from sediments are easily released into the water or pore water. In July, the water levels of Taihu Lake are highest, which causes the heavy metal concentrations in sediments to decrease. In addition, aquatic life (aquatic plants, algae, soft coral animal, microbes, etc.) are actively growing and absorbing heavy metals directly from the water and sediment. The reduction of heavy metals in the water also results in the heavy metals in sediments being released into the water. Benthic disturbance causes the transformation of heavy metals from sediments into water.

Figure 2 shows the total $\mathrm{Pb}, \mathrm{Cu}, \mathrm{Zn}, \mathrm{Cd}, \mathrm{Ni}$, and $\mathrm{Cr}$ contents for the five sites during different seasonal periods in 2009 and 2010. Using one-way ANOVA analysis the heavy metal contents results in sediments show that for $\mathrm{Pb}, \mathrm{Zn}, \mathrm{Cr}$, and $\mathrm{Cu}$, station 3 was significantly different from the other four sites $(\mathrm{p}<0.05)$ and significantly greater than the other four stations. For heavy metals $\mathrm{Cd}, \mathrm{Zn}, \mathrm{Pb}, \mathrm{Cu}, \mathrm{Ni}$, and $\mathrm{Cr}$ there were no significant differences between stations 4 and 5 
$(p>0.05)$. Because station 3 is near the Large and Brookport estuaries located in HuaZhuang town, which is south of Wuxi and lacks a complete drainage system, sewage and industrial wastewaters were discharged into the port. Corresponding to the high pollution load of the WangYu estuary and the Large and Brookport rivers the heavy metal concentrations were significantly higher than at the other stations. The heavy metal contents in sediment also decreased with
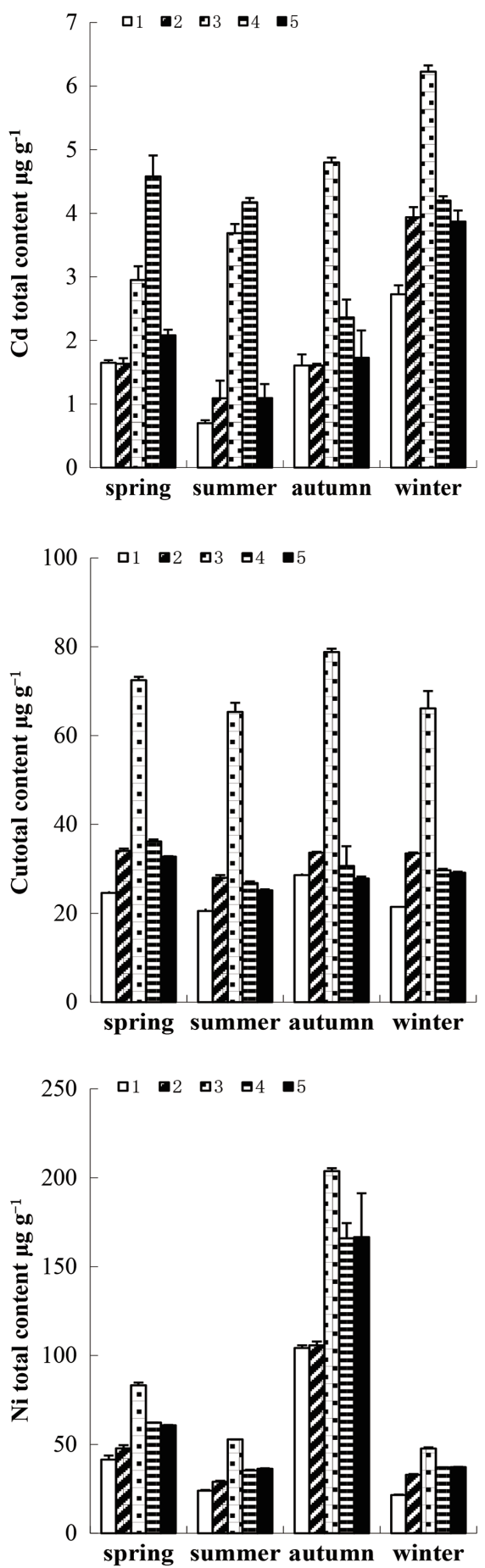

increasing distance from the inflow waters.

\subsubsection{Contamination Factor (CF) and Geo-Accumulation Index (Igeo)}

Sediments have the ability to record the history and indicate the degree of pollution (Pekey et al. 2004). The CF is the ratio between the sediment metal concentration at a
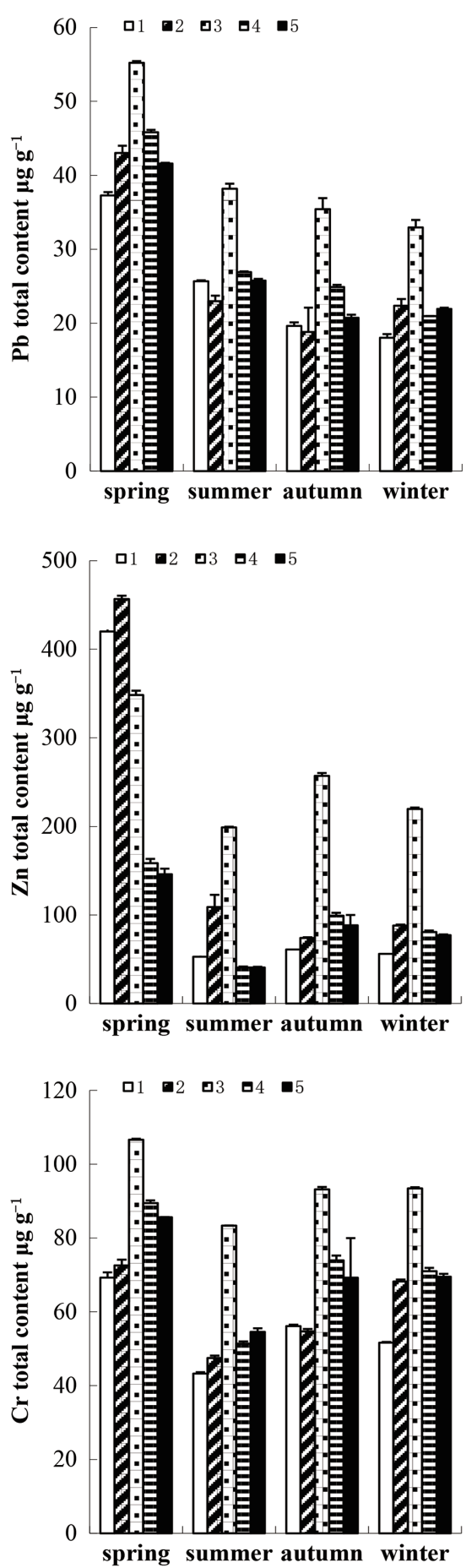

Fig. 2. Total heavy metals contents in different sediments studied over the years 2009 - 2010 collected in different seasonal periods. 
given site and the background value of the metal (Wedepohl 1995). CF is considered to be an effective tool for monitoring pollution over a period of time.

$$
\begin{aligned}
\mathrm{CF}= & \text { Measured concentration of the metal } / \\
& \text { Background value of the metal }
\end{aligned}
$$

This study has revealed that different metals exist at different relative concentrations: $\mathrm{Pb}, 0.90-2.76 ; \mathrm{Cu}, 1.03-3.94$; Zn, $0.62-7.03$; Cd, $7.00-62.3$; Ni, $0.86-2.97$; and $\mathrm{Cr}$ : $0.62-1.52$.

To understand the heavy metal enrichment in Gonghu Bay sediments the CF was determined for all studied metals using continental sediments as the background values. When the CF is $>1$ for a particular metal it means that the sediment is contaminated by that element and if $\mathrm{CF}$ is $<1$, there is no metal enrichment from natural or anthropogenic sources (Muthu Raj and Jayaprakash 2008). The present study shows that only $\mathrm{Cd}$ and $\mathrm{Cu}$ had significant enrichment, while all of the other metals remained within the less contaminated to uncontaminated ranges.

The Igeo was originally defined by Müller (1969) and is a quantitative measure of the metal pollution in aquatic sediments:

$$
\text { Igeo }=\log _{2} \mathrm{Cn} / 1.5 \mathrm{Bn}
$$

where $\mathrm{Cn}$ is the measured content of the element and $\mathrm{Bn}$ is the background value of the same element (Wedepohl 1995). Igeo was used to understand the heavy metal concentrations in the sediments at different stations in Gonghu Bay and the background content of heavy metals in continental sediments.

According to Loska et al. (2004) the contamination level may be classified on a scale that ranges from 1 to 6 , as shown in Table 4. The current Igeo results (Table 5) revealed that the Gonghu Bay sediments generally remained unpolluted to moderately polluted because most of the Igeo values were less than 1 . This was similar to the previous research. They also found that these high heavy metal concentrations were ascribed to the discharge of untreated and partially treated industrial waste water. Gonghu Bay was less polluted with heavy metals (Qu et al. 2001; Huang et al. 2009). Nearly all of the sediments were shown to be moderately to strongly polluted by $\mathrm{Cd}$.

In general, the main sources of $\mathrm{Cd}$ pollution were due to anthropogenic sources, including mining, fertilizers used in agricultural activities (Zheng et al. 2009) and industrial activities (Lin et al. 2002). In particular the stabilizer frequently used by the rubber factory produces much $\mathrm{Cd}$. The $\mathrm{CF}$ and Igeo have also doubtlessly indicated that Gonghu Bay is unpolluted to moderately polluted, with the exception of $\mathrm{Cd}$.

\subsection{Sequential Extraction of Heavy Metals}

Figure 3 reports the heavy metals fractions $(\mathrm{Cd}, \mathrm{Cu}, \mathrm{Pb}$, $\mathrm{Zn}$, and $\mathrm{Ni}$ ) (Cr not shown) in the sediments for four seasonal periods. A multifactor analysis of variance was carried out to evaluate the differences between the four fractions, F1, $\mathrm{F} 2, \mathrm{~F} 3$, and F4, for each metal and the influence of sediment types and seasonal periods. The results shown in Table 6 indicate the highest percentage of the residual fraction metals (F4) was for Cr. Significant differences were found between the distribution fractions for all metals, as indicated by the LSD values at a confidence level of $95 \%$. Furthermore, the multifactor analysis showed significant differences between the distribution fractions of metals considered together ( $p<0.001$ ), but the distribution fractions of metals at different sites and seasonal periods were statistically similar.

Table 4. Geo-accumulation indexes and contamination level.

\begin{tabular}{cl}
\hline Igeo values & \multicolumn{1}{c}{ contamination level } \\
\hline$\leq 0$ & unpolluted \\
$<1$ & unpolluted to moderately polluted \\
$<2$ & moderately polluted \\
$<3$ & moderately to strongly polluted \\
$<4$ & strongly polluted \\
$<5$ & strongly to very strongly polluted \\
$\geq 5$ & very strongly polluted \\
\hline
\end{tabular}

Table 5. Geo-accumulation indexes of different metals at four seasons.

\begin{tabular}{ccccccc}
\hline Season & Igeo $(\mathbf{P b})$ & Igeo $(\mathbf{C u})$ & Igeo $(\mathbf{Z n})$ & Igeo $(\mathbf{N i})$ & Igeo $(\mathbf{C r})$ & Igeo $(\mathbf{C d})$ \\
\hline spring & 0.18 & 0.17 & 0.08 & 0.14 & 0.06 & 8.32 \\
summer & 0.16 & 0.17 & 0.06 & 0.12 & 0.05 & 5.78 \\
autumn & 0.15 & 0.17 & 0.07 & 0.17 & 0.06 & 7.54 \\
winter & 0.15 & 0.17 & 0.07 & 0.12 & 0.06 & 13.44 \\
\hline
\end{tabular}



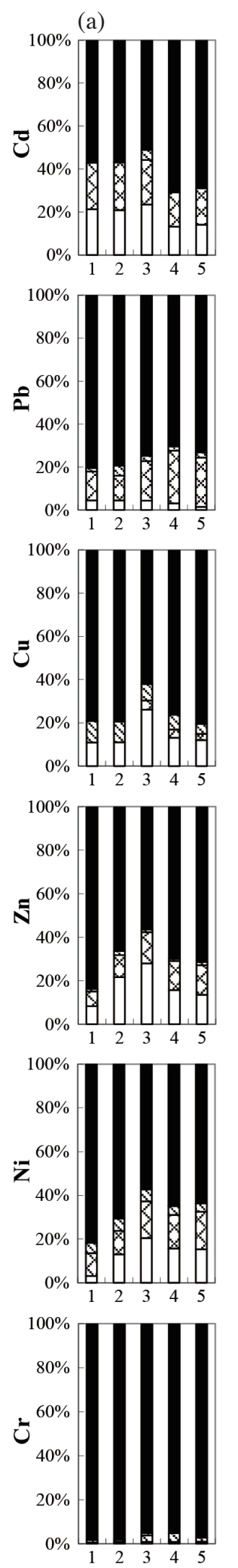

(b)
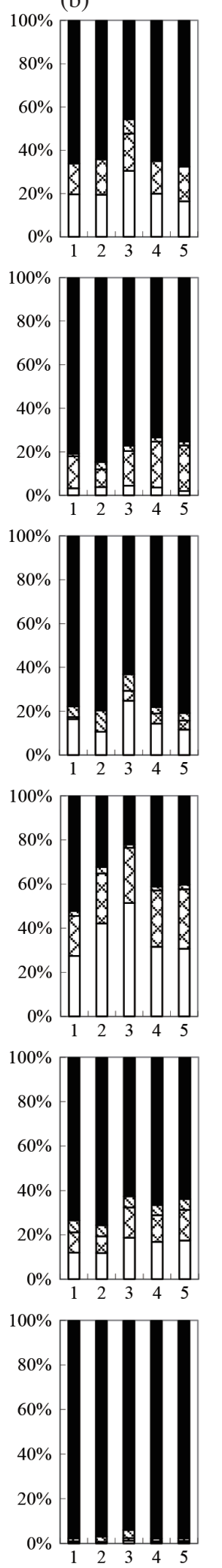

(c)
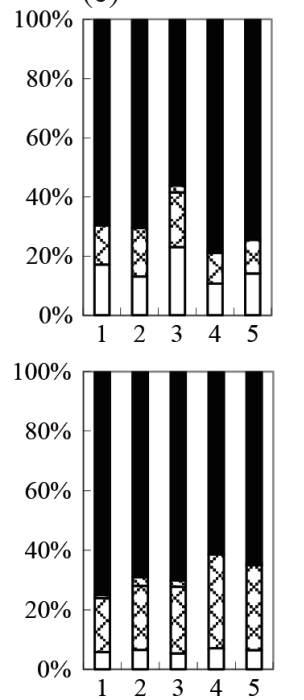

(d)
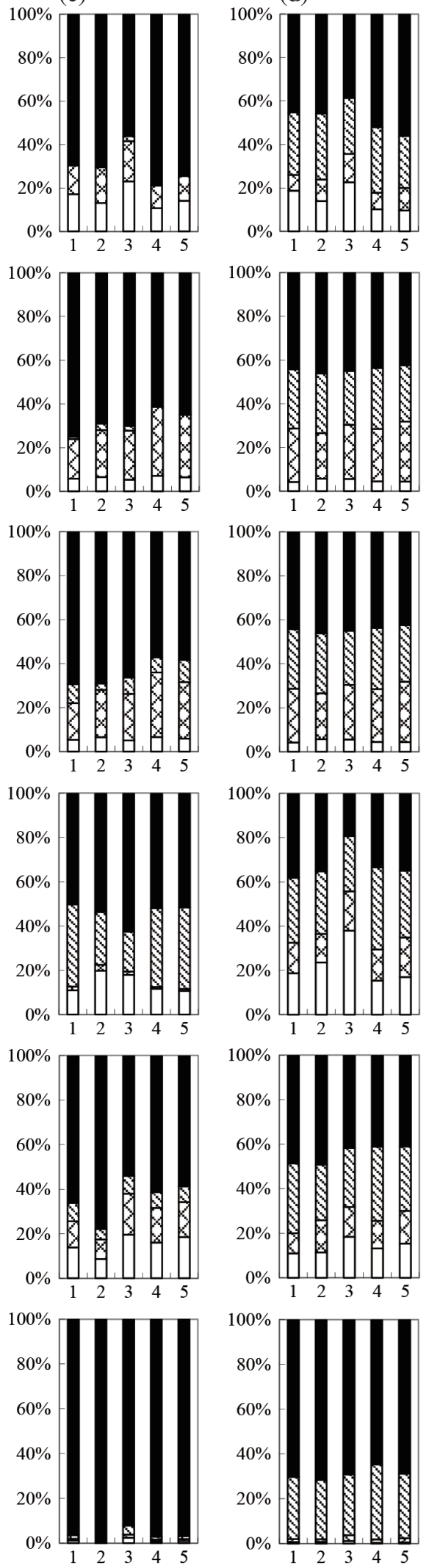
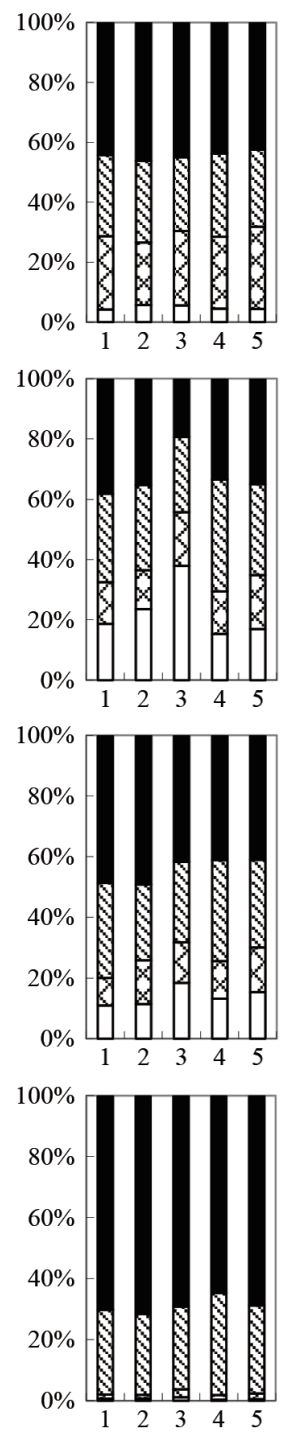

Fig. 3. Fractions of heavy metals expressed as percentages of total amount in sediments at different sites and in different seasonal periods: Spring (a), Summer (b), Autumn (c), Winter (d). 
Table 6. Average values of metal fractions of exchangeable (F1), Reducible (F2), Oxidizable (F3), and Residual (F4) components of the sediments studied.

\begin{tabular}{ccrrrrr}
\hline Fractions & $\mathbf{C d}$ & \multicolumn{1}{c}{$\mathbf{P b}$} & $\mathbf{C u}$ & $\mathbf{Z n}$ & $\mathbf{N i}$ & $\mathbf{C r}$ \\
\hline F1 & 22.18 & 5.38 & 18.00 & 24.27 & 15.96 & 1.13 \\
F2 & 17.56 & 22.71 & 5.59 & 14.41 & 14.47 & 1.04 \\
F3 & 6.07 & 8.90 & 14.81 & 13.63 & 12.03 & 8.90 \\
F1 + F2 + F3 & 45.81 & 36.99 & 38.40 & 52.31 & 42.46 & 11.07 \\
F4 & 54.19 & 63.01 & 61.59 & 47.69 & 57.53 & 88.93 \\
LSD & 7.28 & 6.60 & 5.32 & 6.33 & 3.25 & 5.69 \\
\hline
\end{tabular}

\subsubsection{Different Forms and Bioavailability Analysis}

Content changes could be observed for each metal between the chemical distribution fractions for sediments collected at different sites and during different seasonal periods, as seen in Fig. 3. A significant proportion of $\mathrm{Cd}$, $10-25 \%$, was in the 'easily mobile', exchangeable form, with the highest values of exchangeable $\mathrm{Cd}$ found at site 3 (Fig. 3). Other authors (McGrath and Cegarra 1992; Berti and Jacobs 1996; Zinati et al. 2004) also found high percentages of the water-soluble and exchangeable forms of $\mathrm{Cd}$ in biosolid compost-treated soils. Despite the low total Cd concentrations in the sediments studied, the high solubility of $\mathrm{Cd}$ indicates that this element could cause environmental damage. Therefore, the rate of sediment application should be taken into account.

$\mathrm{Pb}$ appeared to exist primarily in its reducible form at $10-30 \%$ of all samplings. A large amount of $\mathrm{Pb}$ was also recovered in the residual form $(40-80 \%)$ (Fig. 3) which shows that $\mathrm{Pb}$ easily to combined with $\mathrm{Fe}-\mathrm{Mn}$ oxide. This finding agreed with the results from Wong et al. (2001), who reported that $\mathrm{Pb}$ was mainly associated with the primary minerals in sewage sludge. There was a significant variation from spring to winter.

The reducible extracted form of $\mathrm{Cu}$ was low $(0.8-6 \%)$ in spring and summer and then increased significantly in autumn and winter for all samplings. $\mathrm{Cu}$ appeared to be associated with the Fe-Mn-oxide form, up to $30 \%$, and the residual form for $35-45 \%$, particularly in winter. This was in agreement with the common view that $\mathrm{Cu}$ was preferentially associated with organic matter (Illera et al. 2000; Wong et al. 2001). The highest values of extractable form $\mathrm{Cu}$ were found at stations 3 and 4 .

$\mathrm{Zn}$ showed a relatively high availability, with percentages of the labile form amounting to more than 50\%. However, a significant amount of $\mathrm{Zn}$ was extracted using dilute acid, especially at station 3 in the summer, which shows a significant association with carbonates, similar to $\mathrm{Cd}$. In the summer, the fractions of $\mathrm{Zn}$ existed mainly in the exchange- able and reducible forms.

$\mathrm{Ni}$ appeared to be mainly concentrated in the residual fraction, $40-60 \%$, and in the Fe-Mn-bound fraction, $5-20 \%$. The contents of total extracted metal $(\mathrm{F} 1+\mathrm{F} 2+\mathrm{F} 3)$ were relatively high at stations 3,4 , and 5 . There was an increase in the amount of $\mathrm{Ni}$ recovered in the reducible fraction between spring and winter. Compared to other metals, $\mathrm{Ni}$ was most similar to $\mathrm{Cu}$.

$\mathrm{Cr}$ had the lowest availability. The element extraction was low, $0.8-9.2 \%$, and most of the element was recovered in the residual fraction, $75-95 \%$. Therefore, the greatest concentration of $\mathrm{Cr}$ existed in an insoluble form in all the sediments. Wong et al. (2001) also reported that most $\mathrm{Cr}$ existed in the residual phase.

Generally, most of the heavy metals existed in the residual phase. Significant differences were found between station 3 and the other four stations for all metals. There was a significant increase in the content of total extracted metal in the winter.

\subsubsection{Ratio of Secondary and Primary Phrase (RSP)}

When the water environment suffers pollution, heavy metals from human sources are adsorbed onto particle surfaces or combine with organic matter and exist in weak combined phases. Chen proposed the method of the ratio between the secondary and primary phrase (RSP) in 1987. This method is used to evaluate potential ecological risks:

$R S P=M_{\mathrm{sec}} / M_{\text {prim }}$

where $R S P$ refers to pollution levels, $M_{\text {sec }}$ is the heavy metal content in the secondary phase, and $M_{\text {prim }}$ is the heavy metal content of the primary phase. The secondary phase is the content of total extracted metal, $M_{s e c}=\mathrm{F} 1+\mathrm{F} 2+\mathrm{F} 3$, and the primary phase is the residual value, $M_{\text {prim }}=\mathrm{F} 4$. When $R S P<1$, the water is considered unpolluted; $1 \leq R S P<2$ corresponds to lightly polluted; $2 \leq R S P<3$ indicates moderately to strongly polluted; and $R S P \geq 3$ indicates strongly polluted.

We calculated RSP for $\mathrm{Cd}, \mathrm{Cu}, \mathrm{Pb}, \mathrm{Zn}, \mathrm{Ni}$, and $\mathrm{Cr}$ in the sediments of Gonghu Bay. From Fig. 4, the RSP was less than 1 for $\mathrm{Cr}$ in all samplings, so the area is not polluted with $\mathrm{Cr}$, according to the standards of the evaluation. For all the heavy metals the RSP increased significantly in winter. $\mathrm{Pb}, \mathrm{Zn}, \mathrm{Cu}$, and $\mathrm{Ni}$ were greater than 1 , showing light pollution. Zheng et al. (2009) found that, for Fe, $\mathrm{Zn}, \mathrm{Mn}$, and $\mathrm{Cu}$, there were significant variations from spring to winter in the study of Chaohu Lake. The order of potential ecological risks for eight heavy metals from large to small risk was $\mathrm{Zn}>\mathrm{Cu}>\mathrm{Ni}>\mathrm{Pb}>\mathrm{Cd}>\mathrm{Cr}$.

Using one-way ANOVA analysis there were significant differences between station 3 and the other four stations. The 

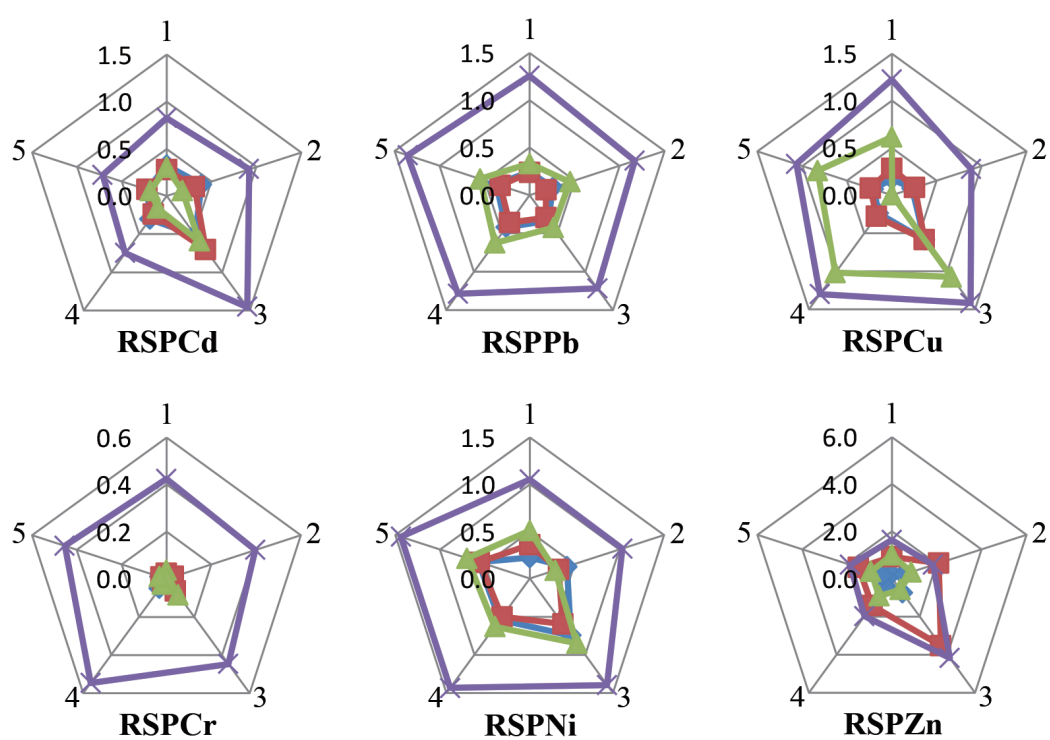

RSPNi

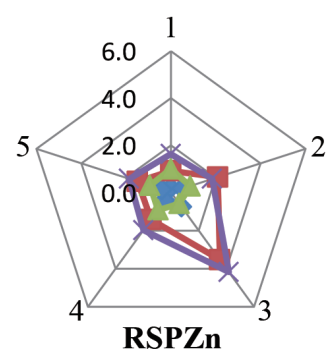

RSPZn

- Spring $\rightarrow$-Summer $\leftarrow$ Autumn $\nsucc$ Winter

Fig. 4. Ratios of secondary and primary phase heavy metals at different stations in Gonghu Bay.

values of $\mathrm{Cu}, \mathrm{Zn}, \mathrm{Cd}, \mathrm{Cr}$, and $\mathrm{Ni}$ (except in winter) were the highest at station 3 and had the most severe potential risk. For $\mathrm{Pb}$, station 5 was different than the other four stations but not significantly, while there were no obvious differences between station 1 and the other four stations. We also found that winter was significantly different from the other seasons. The RSP increased in winter for all the heavy metals. Therefore, station 3 had the highest potential ecological risk, followed by station 5 . To reduce risks, we must pay attention to the changes in heavy metal forms in winter.

\section{CONCLUSIONS}

The analyses of heavy metals $(\mathrm{Cd}, \mathrm{Cr}, \mathrm{Cu}, \mathrm{Ni}, \mathrm{Pb}$, and $\mathrm{Zn}$ ) in sediment samples taken from five stations across Gonghu Bay in Taihu Lake during different seasonal periods indicated that the heavy metal contents showed significant spatial and time variations. The contents of $\mathrm{Pb}, \mathrm{Zn}, \mathrm{Cr}$, and $\mathrm{Cu}$ were significantly higher at station 3 than at the other four stations ( $\mathrm{p}<0.05$ ), which could be related to point source discharges due to the rapid urbanization and economic development occurring in Wuxi. The contents of $\mathrm{Cd}$ and $\mathrm{Zn}$ were above background levels in the study area, while contents of $\mathrm{Cu}, \mathrm{Pb}$, and $\mathrm{Cr}$ were generally within background concentration ranges. The $\mathrm{Pb}, \mathrm{Zn}, \mathrm{Cu}, \mathrm{Cr}$, and $\mathrm{Cd}$ contents were highest in spring (Cd was the highest), probably because the temperature, $\mathrm{pH}$, and $\mathrm{Eh}$ in the lake during spring were in moderate ranges and the heavy metals in the sediments were enriched under these chemical conditions. The $\mathrm{Pb}, \mathrm{Cd}$, and $\mathrm{Cr}$ heavy metal contents were lowest during the autumn, possibly because the water temperature of Taihu Lake was higher in autumn and Eh was relatively high, which easily promotes the release of heavy metals from sediments into the water or pore water. The $\mathrm{CF}$ values showed that only $\mathrm{Cd}$ and $\mathrm{Cu}$ were significantly enriched, while all other metals remained within the less contaminated to uncontaminated states. The Igeo values showed that almost all of the sediments were moderately or strongly polluted by $\mathrm{Cd}$.

This study also suggests that metal contamination cannot be simply evaluated by examining the metal concentrations alone. The extraction of heavy metals should be considered in order to provide a more accurate appraisal of the transportation of metals from anthropogenic sources. Significant differences among the distribution fractions of metals were found when considered together, and for each individual metal, significant differences were observed between the distribution fractions of sediments collected at different sites and during different seasonal periods. Significant differences were found among station 3 and the other four stations for all metals. There was a significant increase in the total extracted metal content in winter. Based on the relative amounts of $\mathrm{Zn}$ and $\mathrm{Cd}$ released in the first two extraction steps $(\mathrm{F} 1+\mathrm{F} 2)$, it could be assumed that these metals could have moderate mobility in soil-water systems. However, most of the metals were found in their residual forms. $\mathrm{Ni}$ and $\mathrm{Zn}$ were in an active state, so their forms can be transformed easily. For all of the heavy metals, the RSP increased in winter, which should be considered fully in order to control the transformation of stable patterns into easily released forms. However, with the Water Transfer Project the river flow patterns and sediment dynamics are expected to be affected. It will be necessary to consider the effects of the Water Transfer Project in the future in order to minimize negative environmental impacts. 
Acknowledgment We are grateful for the grants from the National Natural Science Funds for Distinguished Young Scholar (No.51225901), the Jiangsu Province Science Fund for Distinguished Young Scholar (BK2012037), and the Jiangsu Qinglan Project. The comments and suggestions made by the Anonymous Reviewers are acknowledged.

\section{REFERENCES}

Alloway, B. J. and D. C. Ayres, 1997: Chemical Principles of Environmental Pollution, 2 edition, CRC Press Inc., London, $416 \mathrm{pp}$.

Arnason, J. G. and B. A. Fletcher, 2003: A 40+ year record of $\mathrm{Cd}, \mathrm{Hg}, \mathrm{Pb}$, and $\mathrm{U}$ deposition in sediments of Patroon Reservoir, Albany County, NY, USA. Environ. Pollut., 123, 383-391, doi: 10.1016/S0269-7491(03)00015-0. [Link]

Berti, W. R. and L. W. Jacobs, 1996: Chemistry and phytotoxicity of soil trace elements from repeated sewage sludge applications. J. Environ. Qual., 25, 1025-1032, doi: 10.2134/jeq1996.00472425002500050014x. [Link]

Chen, J. S., L. Dong, and B. S. Deng, 1987: Modeling study on copper partitioning in sediments, a case study of Pongyang Lake. Ac. Sci. Circum., 7, 140-149. (in Chinese)

Chen, M., X. Li, Q. Yang, G. Zeng, Y. Zhang, D. Liao, J. Liu, J. Hu, and L. Guo, 2008: Total concentrations and speciation of heavy metals in municipal sludge from Changsha, Zhuzhou and Xiangtan in middle-south region of China. J. Hazard. Mater., 160, 324-329, doi: 10.1016/j.jhazmat.2008.03.036. [Link]

De Miguel, E., M. J. de Grado, J. F. Llamas, A. Martín-Dorado, and L. F. Mazadiego, 1998: The overlooked contribution of compost application to the trace element load in the urban soil of Madrid (Spain). Sci. Total.Environ., 215, 113-122, doi: 10.1016/S0048-9697(98)00112-0. [Link]

Guven, D. E. and G. Akinci, 2013: Effect of sediment size on bioleaching of heavy metals from contaminated sediments of Izmir Inner Bay. J. Environ. Sci., 25, 17841794, doi: 10.1016/S1001-0742(12)60198-3. [Link]

Fan, C., J. Ji, W. Zhang, Q. Wu, K. Chen, and Y. Chen, 1997: Comprehensive evaluation and preliminary prediction for water quality and eutrophication of Gonghu Bay. T. Oceanol. Limn., 3, 19-22. (in Chinese)

Fan, C. X. and L. Zhang, 2009: Pollution and repair principle in the sediment of Taihu Lake, Beijing Science Publishing Company, 65-68. (in Chinese)

Förstner, U., 1993: Metal speciation - general concepts and applications. Int. J. Environ. An. Ch., 51, 5-23, doi: 10.1080/03067319308027608. [Link]

Hellweg, S., U. Fischer, T. B. Hofstetter, K. Hungerbühler, 2005: Site-dependent fate assessment in LCA: Transport of heavy metals in soil. J. Clean. Prod., 13, 341-
361, doi: 10.1016/j.jclepro.2003.10.003. [Link]

Horowitz, A. J. and K. A. Elrick, 1987: The relation of stream sediment surface area, grain size and composition to trace element chemistry. Appl. Geochem., 2, 437-451, doi: 10.1016/0883-2927(87)90027-8. [Link]

Huang, S., J. Tu, H. Liu, M. Hua, Q. Liao, J. Feng, Z. Weng, and G. Huang, 2009: Multivariate analysis of trace element concentrations in atmospheric deposition in the Yangtze River Delta, East China. Atmos. Environ., 43, 5781-5790, doi: 10.1016/j.atmosenv.2009.07.055. [Link]

Illera, V., I. Walter, P. Souza, and V. Cala, 2000: Short-term effects of biosolid and municipal solid waste applications on heavy metals distribution in a degraded soil under a semi-arid environment. Sci. Total Environ., 255, 29-44, doi: 10.1016/S0048-9697(00)00444-7. [Link]

Jin, C. W., S. J. Zheng, Y.F. He, G. D. Zhou, and Z. X. Zhou, 2005: Lead contamination in tea garden soils and factors affecting its bioavailability. Chemosphere, 59, 11511159, doi: 10.1016/j.chemosphere.2004.11.058. [Link]

Jin, Z., H. Cheng, L. Chen, X. Li, G. Zhu, G. Zhuang, and N. Qian, 2010: Concentrations and contamination trends of heavy metals in the sediment cores of Taihu Lake, East China, and their relationship with historical eutrophication. Chin. J. Geochem., 29, 33-41, doi: 10.1007/ s11631-010-0033-x. [Link]

Kabata-Pendias, A. and H. Pendias, 2001: Trace Elements in Soils and Plants, CRC Press, Florida, USA, $432 \mathrm{pp}$.

Kuo, S., M. S. Lai, and C. W. Lin, 2006: Influence of solution acidity and $\mathrm{CaCl}_{2}$ concentration on the removal of heavy metals from metal-contaminated rice soils. Environ. Pollut., 144, 918-925, doi: 10.1016/j. envpol.2006.02.001. [Link]

Li, Y. T., T. Becquer, J. Dai, C. Quantin, and M. F. Benedetti, 2009: Ion activity and distribution of heavy metals in acid mine drainage polluted subtropical soils. Environ. Pollut., 157, 1249-1257, doi: 10.1016/j. envpol.2008.11.050. [Link]

Lin, S., I. J. Hsieh, K. M. Huang, and C. H. Wang, 2002: Influence of the Yangtze River and grain size on the spatial variations of heavy metals and organic carbon in the East China Sea continental shelf sediments. Chem. Geol., 182, 377-394, doi: 10.1016/S0009-2541(01)00331-X. [Link]

Lim, H. S, J. S. Lee, H. T. Chon, and M. Sager, 2008: Heavy metal contamination and health risk assessment in the vicinity of the abandoned Songcheon Au-Ag mine in Korea. J. Geochem. Explor., 96, 223-230, doi: 10.1016/j.gexplo.2007.04.008. [Link]

Liu, Y., H. C. Guo, Y. J. Yu, K. Huang, and Z. Wang, 2007: Sediment chemistry and the variation of three altiplano lakes to recent anthropogenic impacts in south-western China. Water SA, 33, 305-310. 
Loska, K., D. Wiechuła, and I. Korus, 2004: Metal contamination of farming soils affected by industry. Environ. Int., 30, 159-165, doi: 10.1016/S0160-4120(03)001570 . [Link]

McGrath, S. P. and J. Cegarra, 1992: Chemical extractability of heavy metals during and after long-term applications of sewage sludge to soil. Eur. J. Soil Sci., 43, 313321, doi: 10.1111/j.1365-2389.1992.tb00139.x. [Link]

McLaren, S. J. and N. D. Kim, 1995: Evidence for a seasonal fluctuation of arsenic in New Zealand's longest river and the effect of treatment on concentrations in drinking water. Environ. Pollut., 90, 67-73, doi: 10.1016/0269-7491(94)00092-R. [Link]

Müller, G., 1969: Index of geoaccumulation in sediments of the Rhine River. Geo. J., 2, 108-118.

Muthu Raj, S. and M. Jayaprakash, 2008: Distribution and enrichment of trace metals in marine sediments of Bay of Bengal, off Ennore, south-east coast of India. Environ. Geol., 56, 207-217, doi: 10.1007/s00254-0071156-1. [Link]

O’Reilly Wiese, S. B., R. H. C. Emmerson, C. L. Macleod, and J. N. Lester, 1997: Trends in the solid phase partitioning of metals in the Thames Estuary sediments during recent decades. Estuaries, 20, 494-503, doi: 10.2307/1352609. [Link]

Pekey, H., D. Karakas, S. Ayberk, L. Tolun, and M. Bakoğlu, 2004: Ecological risk assessment using trace elements from surface sediments of İzmit Bay (Northeastern Marmara Sea) Turkey. Mar. Pollut. Bull., 48, 946-953, doi: 10.1016/j.marpolbul.2003.11.023. [Link]

Qu, W., D. Mike, and S. Wang, 2001: Multivariate analysis of heavy metal and nutrient concentrations in sediments of Taihu Lake, China. Hydrobiologia, 450, 8389, doi: 10.1023/A:1017551701587. [Link]

Shen, J. H., B. Gutendorf, H. H. Vahl, L. Shen, and J. Westendorf, 2001: Toxicological profile of pollutants in surface water from an area in Taihu Lake, Yangtze Delta. Toxicology, 166, 71-78, doi: 10.1016/S0300483X(01)00439-5. [Link]

Singh, K. P., D. Mohan, V. K. Singh, A. Malik, 2005: Studies on distribution and fractionation of heavy metals in Gomti river sediments-a tributary of the Ganges, India. J. Hydrol., 312, 14-27, doi: 10.1016/j. jhydrol.2005.01.021. [Link]

Terry, R. E., D. W. Nelson, and L. E. Sommers, 1979: Decomposition of anaerobically digested sewage sludge as affected by soil environmental conditions. J. Environ. Qual., 8, 342-347, doi: 10.2134/ jeq1979.00472425000800030016x. [Link]
Wang, C., X. C. Li, H. T. Ma, J. Qian, and J. B. Zhai, 2006: Distribution of extractable fractions of heavy metals in sludge during the wastewater treatment process. J. Hazard. Mater., 137, 1277-1283, doi: 10.1016/j. jhazmat.2006.04.026. [Link]

Wedepohl, K. H., 1995: The composition of the continental crust. Geochim. Cosmochim. Acta, 59, 1217-1232, doi: 10.1016/0016-7037(95)00038-2. [Link]

Wong, J. W. C., K. Li, M. Fang, and D. C. Su, 2001: Toxicity evaluation of sewage sludges in Hong Kong. Environ. Int., 27, 373-380, doi: 10.1016/S0160-4120(01)000885. [Link]

Yang, Y., F. Chen, L. Zhang, J. Liu, S. Wu, and M. Kang, 2012: Comprehensive assessment of heavy metal contamination in sediment of the Pearl River Estuary and adjacent shelf. Mar. Pollut. Bull., 64, 1947-1955, doi: 10.1016/j.marpolbul.2012.04.024. [Link]

Yang, Z., Y. Wang, Z. Shen, J. Niu, and Z. Tang, 2009: Distribution and speciation of heavy metals in sediments from the mainstream, tributaries, and lakes of the Yangtze River catchment of Wuhan, China. J. Hazard. Mater., 166, 1186-1194, doi: 10.1016/j. jhazmat.2008.12.034. [Link]

Yao, S. and B. Xue, 2010: Nutrients and heavy metals in multi-cores from Zhushan Bay at Taihu Lake, the largest shallow lake in the Yangtze Delta, China. Quat. Int., 226, 23-28, doi: 10.1016/j.quaint.2010.01.004. [Link]

Yuan, H. Z., J. Shen, and E. F. Liu, 2011: Assessment and Characterization of Heavy Metals and Nutrients in Sediments from Taihu Lake. Acta Sci. Circumstantiae, 32, 649-657. (in Chinese)

Yuan, X. Y., A. H. Wang, and N. Z. Xu, 2004: Chemical partitioning of heavy metals and their characteristics for sediments from Lake Taihu. Geochimica, 33, 611618. (in Chinese)

Zhai, S., W. Hu, and Z. Zhu, 2010: Ecological impacts of water transfers on Lake Taihu from the Yangtze River, China. Ecol. Eng., 36, 406-420, doi: 10.1016/j.ecoleng.2009.11.007. [Link]

Zheng, L., Y. Liu, X. Qian, and X. Shi, 2009: The characteristics and regional differences of heavy metal contents in the sediments of Taihu Lake and Chaohu Lake. Environ. Chem., 28, 883-888. (in Chinese)

Zinati, G. M., Y. Li, H. H. Bryan, R. S. Mylavarapu, and M. Codallo, 2004: Distribution and fractionation of phosphorus, cadmium, nickel, and lead in calcareous soils amended with composts. J. Environ. Sci. Heal. B, 39, 209-223, doi: 10.1081/PFC-120027450. [Link] 